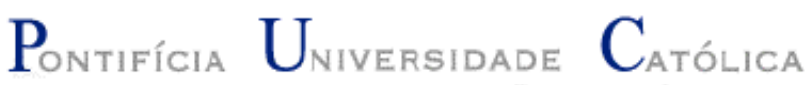

Ranny Alonso de Sousa

\author{
O que é ser administrador de saúde: \\ Estudo exploratório das percepções de \\ executivos do setor
}

Dissertação de Mestrado

Dissertação apresentada ao Programa de Pósgraduação em Administração de Empresas da PUCRio como requisito parcial para obtenção do título de Mestre em Administração de Empresas

Orientadora: Profa . Ana Heloísa da Costa Lemos

Rio de Janeiro

Abril de 2010 


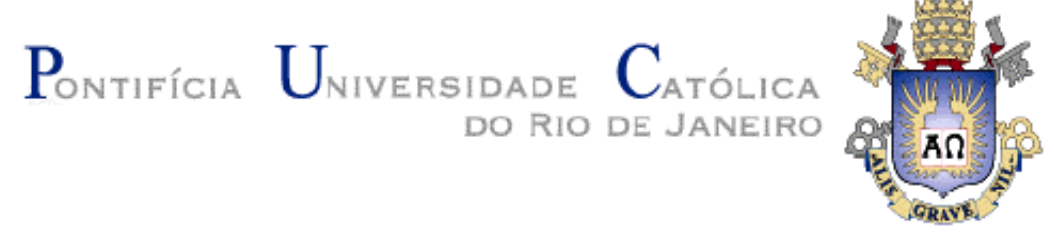

Ranny Alonso de Sousa

\title{
O que é ser administrador de saúde: Estudo exploratório das percepções de executivos do setor
}

\begin{abstract}
Dissertação apresentada como requisito parcial para obtenção do grau de Mestre pelo Programa de Pósgraduação em Administração de Empresas da PUCRio. Aprovada pela Comissão Examinadora abaixo assinada.
\end{abstract}

\author{
Profa. Ana Heloísa da Costa Lemos \\ Orientadora \\ Departamento de Administração - PUC-Rio
}

Prof ${ }^{a}$. Sandra Regina da Rocha Pinto

Departamento de Administração - PUC-Rio

Profa. Flávia de Souza Costa Neves Cavazotte

IBMEC

Prof ${ }^{a}$. Mônica Herz

Vice-Decana de Pós-Graduação do CCS

Rio de Janeiro, 13 de abril de 2010 
Todos os direitos reservados. É proibida a reprodução total ou parcial do trabalho sem autorização da universidade, da autora e da orientadora.

\section{Ranny Alonso de Sousa}

Graduou-se em Comunicação Social na Faculdade Pinheiro Guimarães em 1990. Cursou MBA em Management pela PUC-Rio, em 2000, e em Marketing pelo Coppead-UFRJ, em 2005. Atua como executiva de marketing da Amil Par, empresa a que está ligada desde 1995, onde desenvolve projetos de comunicação e eventos institucionais para os diversos públicos da companhia.

Ficha Catalográfica

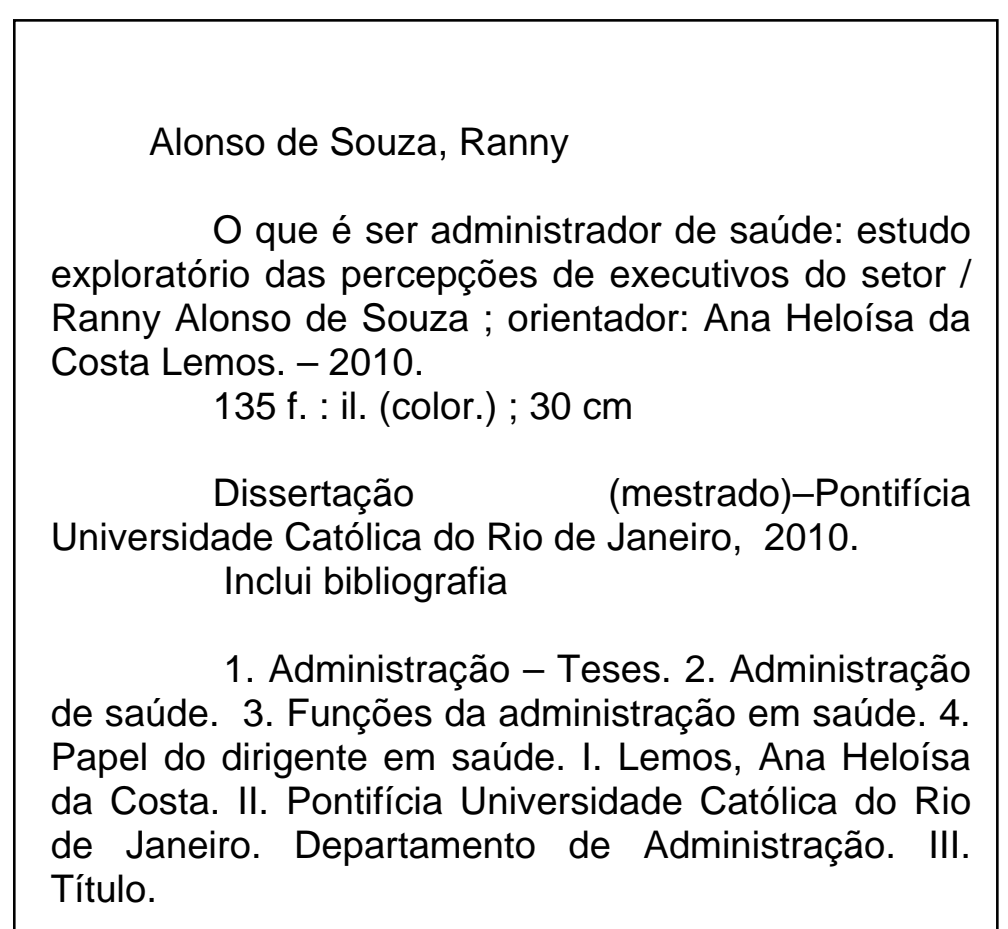

CDD: 658 
Para minha família,o núcleo primitivo,fonte de inspiração, e o núcleo derivado, fonte de motivação. 


\section{Agradecimentos}

A minha orientadora Professora Ana Heloísa da Costa Lemos que direcionou meus esforços com entusiasmo, firmeza e atenção a cada parágrafo.

Aos professores que me inspiraram o que fazer com esta infinita curiosidade pela aventura humana nas organizações: Heloísa Leite e Letícia Cassoti, do CoppeadUFRJ ; Mario Pinto e Sandra Regina da Rocha Pinto, da PUC-Rio e Everardo Rocha, de ambos.

Ao professor José Roberto Gomes, em memória, um jardineiro cujas sementes que cultiva são tão poderosas que germinam na mente e no coração simultaneamente.

Aos amigos de jornada no mestrado com quem tanto aprendi --e me diverti.

Aos executivos que participaram dessa pesquisa, pela franqueza e generosidade em compartilhar sua história pessoal e profissional.

À empresa em que trabalho, que estimula, de verdade, o crescimento e a liberdade de seus profissionais. Na Amil, aprendi que construímos e que somos construídos pelo empreendimento a que nos dedicamos.

A minha família por me ensinar e me lembrar o fundamento de tudo: amor e compromisso.

Ao meu pai e minha mãe, que moldaram minha alegria, empenho e fé.

Aos meus amores Marco e João, com quem tenho tanto prazer em compartilhar a vida.

À Nossa Senhora, cuja completude me emudece. 


\section{Resumo}

Sousa, Ranny Alonso de; Lemos, Ana Heloísa da Costa. O que é ser administrador de saúde: um estudo exploratório das percepções dos executivos do setor. Rio de janeiro, 2010. 135p. Dissertação de Mestrado Departamento de Administração, Pontifícia Universidade Católica do Rio de Janeiro.

A indústria da saúde é gerida, no Brasil, por administradores de saúde que, em grande parte, migraram da atividade médica tradicional para a de gestão. São pessoas que em algum momento de suas carreiras, aceitaram responsabilidades administrativas e assumiram cargos de gestão em um dos mais desafiadores e caros segmentos produtivos da economia. O propósito dessa pesquisa foi procurar desvendar a complexidade do desafio de ser administrador de saúde, a partir da vivência de executivos do sistema de saúde privado, exercendo cargos em operadoras de saúde ou hospitais. A estratégia de investigação escolhida para responder ao problema de pesquisa - o que é ser administrador de saúde? - foi o método fenomenológico. Este método foi considerado adequado por permitir que o entrevistado, com base em sua experiência vivida, formulasse por si próprio seus significados, sem o direcionamento de um roteiro pré-estabelecido. A descrição textual conformou, então, uma descrição da essência da experiência vivida pelos sujeitos entrevistados, agrupada em clusters de significação: a mudança de papéis de médico a médico-administrador, o sentimento de onipotência e tolerância ao próprio erro, a tolerância ao erro da equipe e atenção aos detalhes, a visão do trabalho gerencial, a qualificação da ética e o escopo da gestão de saúde. As entrevistas foram feitas com base em apenas duas perguntas: o que é ser administrador de saúde e que contextos ou situações você considera típicos desta experiência? Pouco se tem escrito, no Brasil, sobre quem toma as decisões que têm impacto em todo o segmento. Nesse contexto, o presente trabalho contribui com insights importantes acerca das ocupações e das preocupações que tomam a agenda do administrador de saúde.

\section{Palavras-chave}

Administração de saúde; funções da administração em saúde; papel do dirigente em saúde. 


\section{Abstract}

Sousa, Ranny Alonso de; Lemos, Ana Heloísa da Costa (Advisor). What consists on being a health manager: an exploratory study about the perceptions of the health industry executives. Rio de janeiro, 2010. 135p. MSc. Dissertation - Departamento de Administração, Pontifícia universidade católica do Rio de Janeiro.

The healthcare industry is managed, in Brazil, for health managers, in large part, who migrated from traditional medical assistance. These are people who at some point in their careers, accepted administrative responsibilities and assumed management positions in one of the most challenging and expensive production segments of the economy. The purpose of this research was to attempt to unravel the complexity of the challenge of being a health manager, from the experience of executives of private health care, acting positions in health insurance companies or hospitals. The research strategy chosen to address the problem of research what consists on being a health manager? - was the phenomenological method. This method was deemed appropriate to allow the interviewee, based on their experience, to formulate their meaning by himself, without the guidance of a preestablished guidance. The textual description conformed, then a description of the essence of lived experience by interviewees, grouped in clusters of meaning: the changing roles of physician to health manager; the sense of omnipotence and tolerance to their own error; the tolerance to staff error and attention to detail; the view of managerial work, the qualification of ethics and scope of healthcare management. The interviews were based on only two questions: what is a health manager and what contexts or situations you consider typical for this experience? Little has been written in Brazil, about who makes decisions that impact the entire segment. In this context, this study contributes important insights about the occupations and preoccupations that take the agenda of health care managers.

\section{Keywords} health.

Health management; management functions in health; the role of leader in 


\section{Sumário}

1. Introdução 13

1.1. O problema de pesquisa 13

$\begin{array}{ll}\text { 1.2. Objetivos } & 18\end{array}$

1.2.1.. Objetivo principal 18

$\begin{array}{ll}\text { 1.2.2. Objetivos intermediários } & 18\end{array}$

$\begin{array}{ll}\text { 1.3. Relevância do estudo } & 18\end{array}$

1.4. Delimitação do estudo 19

1.5. Estrutura da dissertação 20

2. Referencial Teórico 22

2.1. O que é ser administrador 22

2.1.1. O sentido da administração 22

2.1.2. O papel do administrador 24

2.1.3. Administração, racionalidade e intuição 30

2.1.4. As funções do gerente 35

2.1.4.1. Pensar estrategicamente 35

2.1.4.2. Tomar decisões 38

2.1.4.3. Liderar 43

2.1.4.4. Organizar e estruturar 48

2.1.5. Administração: dimensões subjetivas 49

2.2. O que é ser administrador de saúde 51

2.2.1. Organizações de saúde 51

2.2.2. Desafio do setor 59

2.2.3. Modelos e papéis na administração de saúde 62

2.2.3.1. Controle-externo: modelo de propósito racional 64

2.2.3.2. Controle-interno: modelo de processo interno 65

2.2.3.3. Flexibilidade-interno: modelo de relações humanas 67

2.2.3.4. Flexibilidade-externo: modelo de sistema aberto 68

2.2.3.5. Equilíbrio, contingências e percepção dos gestores 70

2.2.4. O médico na administração de saúde 73 
$\begin{array}{ll}\text { 3. Metodologia } & 75\end{array}$

3.1. A compreensão da realidade 75

3.2. A pesquisa qualitativa 76

3.3. A estratégia de investigação adotada 77

3.4. O objeto de estudo 78

$\begin{array}{ll}\text { 3.5. O papel da pesquisadora } & 79\end{array}$

3.6. A pergunta da pesquisa 80

3.7. A escolha dos sujeitos 80

3.8. A coleta e o tratamento dos dados 82

3.9. Limitações do método 84

4. Análise e discussão dos resultados 85

4.1. Mudança de papéis: de médico a médico-administrador 86

4.1.1. Razões pragmáticas $\quad 87$

4.1.2. Aspirações de poder e influência 89

4.1.3. Enfrentamento de críticas externas à mudança 91

4.1.4. Construção gradual do papel do administrador 93

4.2. Sentimento de onipotência e tolerância ao próprio erro 95

4.3. Tolerância ao erro da equipe e atenção aos detalhes 97

4.4. Visão do trabalho gerencial 98

4.4.1. Uso da lógica e da intuição 99

4.4.2. Preocupação constante com recursos, resultados, métodos, $\begin{array}{ll}\text { rotinas e controles } & 101\end{array}$

$\begin{array}{ll}\text { 4.4.3. Necessidade de aprendizado permanente } & 104\end{array}$

4.4.4. Tomada de decisão 107

4.4.5. Negociação 109

4.4.6. Exercício da liderança e trabalho em equipe 112

$\begin{array}{ll}\text { 4.4.7. Abertura á alteridade } & 115\end{array}$

$\begin{array}{ll}\text { 4.5. Qualificação da ética } & 117\end{array}$

$\begin{array}{ll}\text { 4.6. Escopo da gestão de saúde } & 120\end{array}$

$\begin{array}{ll}\text { 5. Conclusão e considerações finais } & 123\end{array}$

6. Referências Bibliográficas 


\section{Lista de figuras}

Figura 1 - A ecologia concêntrica de organizações no setor de assistência à saúde

Figura 2 - Os diferentes mundos de um hospital geral

Figura 3 - Questões em um hospital geral

58

Figura 4 - Estrutura de valores competitivos

64

Figura 5 - Os modelos e os papéis de liderança no Competing Value Framework 


\section{Lista de quadros}

Quadro 1 - Folclores e fatos da administração 27

Quadro 2 - Papéis do administrador 28

Quadro 3 - Área de conhecimento administrativa e sua
importância

Quadro 4 - Transformação do sistema de saúde 60

Quadro 5 - Os modelos, os papéis e as competências da
liderança no Competing Values Framework

Quadro 6 - Identificação de entrevistados e perfis $\quad 81$

Quadro 7 - Clusters de termas e sub 86 
Tudo o que se faz como líder fala sobre você. 